\title{
SARS Coronavirus-2 Microneutralisation and Commercial Serological Assays Correlated Closely for Some but Not All Enzyme Immunoassays
}

\author{
Gregory J. Walker ${ }^{1,2}{ }^{\infty}$, Zin Naing ${ }^{3}$, Alberto Ospina Stella ${ }^{4}{ }^{\circledR}$, Malinna Yeang ${ }^{1,3}$, Joanna Caguicla ${ }^{3}$, \\ Vidiya Ramachandran ${ }^{3}{ }^{\circledR}$, Sonia R. Isaacs ${ }^{1}$, David Agapiou ${ }^{4}$, Rowena A. Bull ${ }^{4}{ }^{\circ}$, Sacha Stelzer-Braid ${ }^{1,2}$, \\ James Daly ${ }^{5}{ }^{(}$, Iain B. Gosbell ${ }^{5,6}$, Veronica C. Hoad ${ }^{5}{ }^{(D}$, David O. Irving ${ }^{5,7} \mathbb{C}^{\text {, Joanne M. Pink }}{ }^{5}$, Stuart Turville ${ }^{4}$, \\ Anthony D. Kelleher ${ }^{4}$ and William D. Rawlinson ${ }^{1,2,3,8, * \text { (D) }}$
}

1 Virology Research Laboratory, Prince of Wales Hospital, Sydney, NSW 2031, Australia; gregory.walker@unsw.edu.au (G.J.W.); Malinna.Yeang@health.nsw.gov.au (M.Y.); sonia.isaacs@unsw.edu.au (S.R.I.); s.stelzer@unsw.edu.au (S.S.-B.)

2 School of Medical Sciences, Faculty of Medicine, University of New South Wales, Sydney, NSW 2052, Australia

3 Serology and Virology Division (SaViD), NSW Health Pathology, Prince of Wales Hospital, Sydney, NSW 2031, Australia; zin.naing@health.nsw.gov.au (Z.N.); joanna.caguicla@health.nsw.gov.au (J.C.); vidiya.ramachandran@health.nsw.gov.au (V.R.)

4 Kirby Institute, University of New South Wales, Sydney, NSW 2052, Australia; aospinastella@kirby.unsw.edu.au (A.O.S.); dagapiou@kirby.unsw.edu.au (D.A.); r.bull@unsw.edu.au (R.A.B.); sturville@kirby.unsw.edu.au (S.T.); akelleher@kirby.unsw.edu.au (A.D.K.)

check for updates

Citation: Walker, G.J.; Naing, Z.; Ospina Stella, A.; Yeang, M.; Caguicla, J.; Ramachandran, V.; Isaacs, S.R.; Agapiou, D.; Bull, R.A.; Stelzer-Braid, S.; et al. SARS Coronavirus-2 Microneutralisation and Commercial Serological Assays Correlated Closely for Some but Not All Enzyme Immunoassays. Viruses 2021, 13, 247. https://doi.org/10.3390/v13020247

Academic Editor: Peng Zhou

Received: 16 December 2020

Accepted: 1 February 2021

Published: 4 February 2021

Publisher's Note: MDPI stays neutral with regard to jurisdictional claims in published maps and institutional affiliations.

Copyright: (c) 2021 by the authors. Licensee MDPI, Basel, Switzerland. This article is an open access article distributed under the terms and conditions of the Creative Commons Attribution (CC BY) license (https:/ / creativecommons.org/licenses/by/ $4.0 /)$.
5 Australian Red Cross Lifeblood, 417 St Kilda Rd, Melbourne, VIC 3004, Australia; jamedaly@redcrossblood.org.au (J.D.); igosbell@redcrossblood.org.au (I.B.G.); vhoad@redcrossblood.org.au (V.C.H.); dirving@redcrossblood.org.au (D.O.I.); jpink@redcrossblood.org.au (J.M.P.)

6 School of Medicine, Western Sydney University, Penrith, NSW 2747, Australia

7 Faculty of Health, University of Technology, Sydney, NSW 2007, Australia

8 School of Biotechnology and Biomolecular Sciences, Faculty of Science, University of New South Wales, Sydney, NSW 2052, Australia

* Correspondence: w.rawlinson@unsw.edu.au; Tel.: +61-2-9382-9188

Abstract: Serological testing for SARS-CoV-2-specific antibodies provides important research and diagnostic information relating to COVID-19 prevalence, incidence and host immune response. A greater understanding of the relationship between functionally neutralising antibodies detected using microneutralisation assays and binding antibodies detected using scalable enzyme immunoassays (EIA) is needed in order to address protective immunity post-infection or vaccination, and assess EIA suitability as a surrogate test for screening of convalescent plasma donors. We assessed whether neutralising antibody titres correlated with signal cut-off ratios in five commercially available EIAs, and one in-house assay based on expressed spike protein targets. Sera from recovered patients or convalescent plasma donors who reported laboratory-confirmed SARS-CoV-2 infection $(n=200)$, and negative control sera collected prior to the COVID-19 pandemic $(n=100)$, were assessed in parallel. Performance was assessed by calculating EIA sensitivity and specificity with reference to microneutralisation. Neutralising antibodies were detected in 166 (83\%) samples. Compared with this, the most sensitive EIAs were the Cobas Elecsys Anti-SARS-CoV-2 (98\%) and Vitros Immunodiagnostic Anti-SARS-CoV-2 (100\%), which detect total antibody targeting the $\mathrm{N}$ and $\mathrm{S} 1$ antigens, respectively. The assay with the best quantitative relationship with microneutralisation was the Euroimmun IgG. These results suggest the marker used (total $\mathrm{Ab}$ vs. IgG vs. IgA) and the target antigen are important determinants of assay performance. The strong correlation between microneutralisation and some commercially available assays demonstrates their potential for clinical and research use in assessing protection following infection or vaccination, and use as a surrogate test to assess donor suitability for convalescent plasma donation.

Keywords: SARS-CoV-2; neutralising antibody; serology; COVID-19; convalescent plasma 


\section{Introduction}

The easing of COVID-19 control measures requires extensive surveillance for the early detection of new clusters, as well as an understanding of the level and duration of protective immunity in the community. Serological testing for SARS-CoV-2-specific antibodies is an important tool that serves multiple diagnostic and research purposes, including (i) confirmation of suspected infection, (ii) informing public health policy by determining the true infection rate (symptomatic and asymptomatic cases) occurring within a population, (iii) assessing seroconversion following infection or vaccination and (iv) as a potential scalable screening test to determine suitability for convalescent plasma donation [1-4].

It is important to decipher the neutralising capability of developed SARS-CoV-2specific antibodies to understand whether the host response will provide sufficient protection from future reinfection. Neutralising antibodies can be detected using the microneutralisation assay and plaque reduction neutralisation test. These assess the ability of patient-derived serum samples containing SARS-CoV2-specific antibody to inhibit infection of cells cultured in vitro [5]. These virus neutralisation tests require the handling of replication-competent SARS-CoV-2 in specialized containment laboratories (biosafety level 3 , at minimum [6]), and for this reason are impractical to scale. Commercially available serology tests, such as enzyme immunoassays (EIA), are faster and less laborious than traditional culture-based methods, which is advantageous in the diagnostic laboratory setting [7]. However, these assays do not differentiate between binding antibodies and neutralising antibodies [8]. The detection of binding antibodies does not necessarily confer virus-neutralisation or protection against virus replication in the infected host, and traditional virus neutralisation tests remain the reference standard [9]. The correlation of binding antibodies detected using EIA with neutralising antibody titres will be crucial for population-level screening of seroconversion and assessment of herd-immunity following vaccination and rapid assessment of the suitability of convalescent plasma donors $[4,10]$.

In response to the demand for SARS-CoV-2 serological testing kits, numerous assays have been released under relaxed regulatory assessment criteria [1]. Validation studies by end-users are important to assess the performance characteristics of these new commercial assays, and to determine the correlation between EIAs and neutralising antibody titres. To date, a small number of studies have validated a range of commercially available SARS$\mathrm{CoV}-2$ serological assays against a live-virus neutralisation test [11-15]. Assays assessed in these publications incorporate automated platforms as well as serology-based point of care tests and have some, but limited, crossover with the comparison of EIAs in the present study. Others tested too few samples to effectively correlate EIA results with neutralising antibody titres [16-20], lacked comparison of head-to-head EIAs [21,22] or used live-virus neutralisation as a reference standard primarily to validate assays developed in-house [23-26]. Here, we report on the performance of a unique set of five commercially available SARS-CoV-2 serological assays and an in-house developed EIA, with reference to a reference-standard microneutralisation assay.

\section{Methods}

\subsection{Sample Collection and Testing}

All samples were received by the Serology and Virology Division at the Prince of Wales Hospital Randwick, Australia. Two hundred sera were collected from laboratoryconfirmed COVID-19 patients $(n=157)$ between March and June of 2020. The majority were recruited as convalescent plasma donors (self-reported laboratory-confirmed infection, $\mathrm{PCR}=154 / 157$, serology $=3 / 157$ ) and tested as part of the release test to ensure donor suitability on behalf of Australian Red Cross Lifeblood (161 samples from 124 donors). Donor samples were collected 37 to 101 days post-test positivity date $($ mean $=60.5)$. The donors ranged in age from 20 to 78 years old (mean $=45.3$ years) with $54.6 \%$ being males. A smaller proportion of serum (39/200) was obtained from COVID-19 patients 1 to 47 days post-laboratory-confirmed diagnosis. An additional 100 sera were obtained 
from patients prior to the COVID-19 pandemic between 2016 and 2018 (control cohort). This included 25/100 samples serologically positive for antibodies to common respiratory viruses (Supplementary Table S1). Antibodies to SARS-CoV-2 in samples were measured using a microneutralisation assay at two dilutions (1:40 and 1:80), and up to six other immunoassays including an in-house developed EIA. Commercially available assays were performed according to the manufacturer's instructions, using kits of the same lot number for all assays. Samples returning equivocal/borderline results (as per the manufacturerspecified range) were not included in sensitivity and specificity calculations.

\subsection{Virus Microneutralisation Assay}

Dilutions of test serum were prepared on a 96-well plate in duplicate in viral culture media (MEM $+2 \%$ fetal bovine serum $+1 \times$ penicillin-streptomycin-glutamine). Included in duplicate on each plate were no-virus negative controls, serum-free positive controls, neutralising control serum and non-neutralising control serum. The dilutions were incubated for one hour at $37^{\circ} \mathrm{C}$ with an equal volume of $200 \mathrm{TCID}_{50}$ SARS-CoV-2 isolate. A suspension of Vero E6 cells containing $2 \times 10^{4}$ cells was added to each well, and plates were incubated at $37{ }^{\circ} \mathrm{C}\left(5 \% \mathrm{CO}_{2}\right)$ for three days. The plates were observed for cytopathic effect and the neutralisation titre determined as the dilution that conferred complete protection from infection in both replicates. Neutralising titres of 1:40 and above were considered positive.

\subsection{Cobas Elecsys Anti-SARS-CoV-2}

Elecsys Anti-SARS-CoV-2 (Roche Diagnostics, Sydney, NSW, Australia) is an electrochemiluminescence immunoassay (ECLIA) for the detection of total antibody against the $\mathrm{N}$ protein of SARS-CoV-2 in serum and plasma. The platform provided a readout indicating whether the sample measurement was above or below the signal cut-off, and was interpreted as positive $(\geq 1.0)$ or negative $(<1.0)$.

\subsection{Vitros Immunodiagnostic Anti-SARS-CoV-2}

Vitros Immunodiagnostic Anti-SARS-CoV-2 (Ortho-Clinical Diagnostics, Melbourne, VIC, Australia) is a chemiluminescent immunoassay (CLIA) utilizing a recombinant SARSCoV-2 S1 protein to measure total antibody present in serum and plasma. The platform provided a readout indicating whether the sample measurement was above or below the signal cut-off, and was interpreted as positive $(\geq 1.0)$ or negative $(<1.0)$.

\subsection{Abbott Architect SARS-CoV-2 IgG}

Architect SARS-CoV-2 IgG (Abbott Diagnostics, Sydney, NSW Australia) is a chemiluminescent microparticle immunoassay (CMIA) for the detection of IgG antibodies to the nucleocapsid (N) protein of SARS-CoV-2 in serum and plasma. The platform calculated a result by dividing the chemiluminescent signal from each sample with a calibrated signal. The unit for the assay is Index (S/C), and the result was interpreted as positive $(\geq 1.4)$ or negative $(<1.4)$.

\subsection{Euroimmun Anti-SARS-CoV-2 ELISA}

Anti-SARS-CoV-2 (Euroimmun, Lübeck, Germany) is an enzyme linked immunosorbent assay (ELISA)-based platform that utilizes recombinant $\mathrm{S} 1$ protein to bind anti-SARS$\mathrm{CoV}-2$ antibodies in serum or plasma. Separate kits for the detection of IgG and IgA were used. Photometric measurement of colour intensity was used to calculate a ratio of the sample over the calibrator. The ratio was interpreted as positive $(\geq 1.1)$, borderline $(\geq 0.8-<1.1)$ or negative $(<0.8)$.

\subsection{In-House RBD Assay}

In-house ELISA was performed by coating 96-well microtiter ELISA plates with biotinylated RBD antigen (Supplementary information), which bound SARS-CoV-2-specific 
antibodies. Diluted serum (1:101) or controls were added to respective wells for one hour. Wells were aspirated and washed three times with wash solution (PBS $+1 \%$ Tween 20). A secondary antibody (antihuman-IgG conjugated with the enzyme alkaline phosphatase, Virion/Serion) was then added to wells for $30 \mathrm{~min}$ to detect and bind the immune complex. The wash step was then repeated, before the addition of substrate solution (p-nitrophenylphosphate, Virion/Serion) for $30 \mathrm{~min}$. The stopping solution was then added $(<0.1 \mathrm{~N}$ sodium hydroxide and $40 \mathrm{mM}$ EDTA, Virion/Serion), and absorbance was read at $405 / 620 \mathrm{~nm}$. The cut-off optical density (OD) was set at 0.2 above the negative control OD. Samples were considered positive if the absorbance value was equal to or higher than the cut-off value.

\subsection{Statistical Analyses}

The performance of the commercial assays was compared using results of the microneutralisation assay as the reference standard. For sensitivity, only microneutralisationpositive samples were used in calculations. Assay specificity and cross-reactivity were assessed using samples from the negative-control cohort. Equivocal results were excluded from sensitivity and specificity calculations. Figures including optical density ratios and ROC curves were generated in Prism (Version 9, GraphPad, San Diego, CA, USA). For the purpose of this analysis, serum collected $\geq 14$ days post-laboratory confirmed that COVID19 diagnosis was considered convalescent.

\section{Results}

Neutralising antibodies were detected in 166/200 (83\%) confirmed COVID-19 sera (Table 1). There were 151/167 (90\%) convalescent sera ( $\geq 14$ days) positive for neutralising antibodies, including $112(67 \%)$ which were neutralising at the highest dilution tested (1:80). No samples in the control cohort were positive for neutralising antibodies.

Across all assays, SARS-CoV-2 antibodies were detected in 182/200 (91\%) samples tested, with individual EIA positivity ranging between 61 and 90\% (Table 1). There were five convalescent sera from NAT-confirmed COVID-19 patients that returned negative results by microneutralisation and all EIAs tested (samples tested on $\geq 3$ EIAs).

The sensitivity values of the commercially available assays against the microneutralisation reference standard ranged from 69 to $100 \%$, with assays measuring total antibody being most sensitive (Table 1). There was little difference in the sensitivity of assays in detecting neutralising antibody between acute and convalescent COVID-19 samples. Optical density ratios for each EIA, at varying neutralising antibody titres, are shown in Figure 1. The Euroimmun IgG assay had the highest positive predictive value $(94 \%)$ and displayed the best quantitative relationship with microneutralisation (Figure 2). All EIAs other than the Euroimmun IgA (94\%) and in-house ELISA (96\%) displayed 100\% specificity in testing the negative control cohort. 
Table 1. Performance of commercially available SARS-CoV-2 serological assays.

\begin{tabular}{|c|c|c|c|c|c|c|c|}
\hline & Microneutralisation & Cobas Total Ab & Vitros Total Ab & Abbott IgG & In-House IgG & Euroimmun IgG & Euroimmun $\operatorname{IgA}$ \\
\hline Platform & Cell culture & ECLIA & CLIA & CMIA & ELISA & ELISA & ELISA \\
\hline Antigen & - & $\mathrm{N}$ & S1 & $\mathrm{N}$ & RBD & S1 & S1 \\
\hline \multicolumn{8}{|l|}{$\begin{array}{l}\text { All COVID-19 } \\
\text { samples }\end{array}$} \\
\hline Total & 200 & 197 & 98 & 199 & 94 & 132 & 96 \\
\hline Positive & 166 & 175 & 88 & 139 & 79 & 106 & 51 \\
\hline Negative & 34 & 22 & 10 & 60 & 11 & 24 & 32 \\
\hline Equivocal & - & - & - & - & 4 & 2 & 13 \\
\hline Sensitivity ${ }^{1}(\%)$ & - & 98.2 & 100.0 & 78.8 & 96.1 & 94.3 & 69.4 \\
\hline \multicolumn{8}{|l|}{$\begin{array}{c}\text { Convalescent } \\
\text { samples }^{2}\end{array}$} \\
\hline Total & 167 & 167 & 73 & 167 & 74 & 109 & 73 \\
\hline Positive & 151 & 160 & 72 & 123 & 65 & 93 & 40 \\
\hline Negative & 16 & 70 & 1 & 43 & 6 & 66 & 24 \\
\hline Equivocal & - & - & - & - & 3 & 2 & 9 \\
\hline Positivity (\%) & 90.4 & 95.8 & 98.6 & 73.7 & 91.5 & 86.9 & 62.5 \\
\hline Sensitivity ${ }^{1}(\%)$ & - & 98.7 & 100.0 & 76.8 & 95.3 & 93.6 & 65.0 \\
\hline Total & 100 & 100 & 99 & 100 & 100 & 100 & 100 \\
\hline Positive & 0 & 0 & 0 & 0 & 4 & 0 & 6 \\
\hline Negative & 100 & 100 & 99 & 100 & 96 & 100 & 92 \\
\hline Equivocal & - & - & - & - & - & - & 2 \\
\hline Specificity ${ }^{1}(\%)$ & 100.0 & 100.0 & 100.0 & 100.0 & 96.0 & 100.0 & 93.9 \\
\hline PPV (\%) & - & 93.7 & 90.9 & 93.5 & 89.2 & 94.3 & 87.7 \\
\hline NPV (\%) & - & 97.5 & 100.0 & 78.1 & 97.2 & 95.1 & 77.3 \\
\hline
\end{tabular}

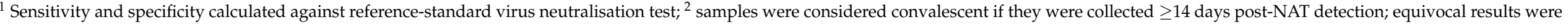

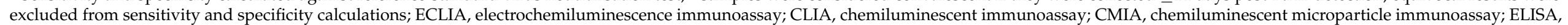
enzyme linked immunosorbent assay; N, nucleoprotein; S1, spike glycoprotein subunit 1; RBD, receptor binding domain; PPV, positive predictive value; NPV, negative predictive value. 
a)

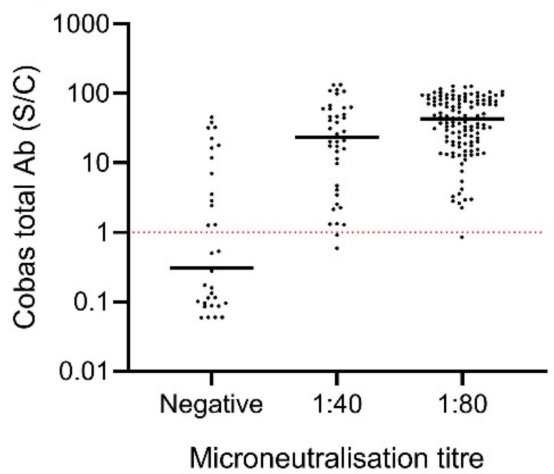

c)

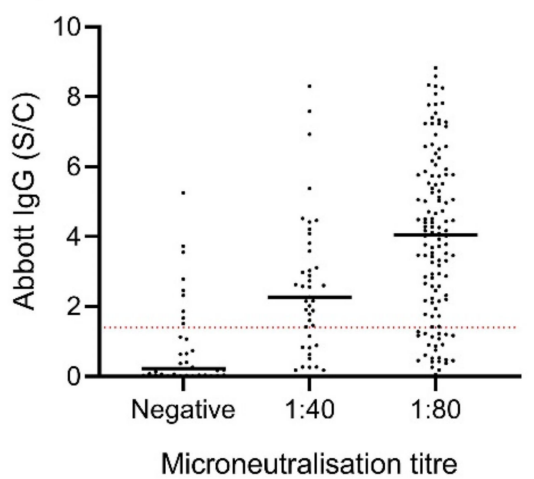

e)

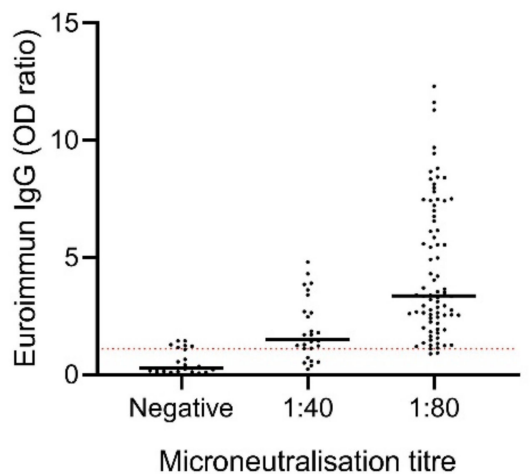

b)

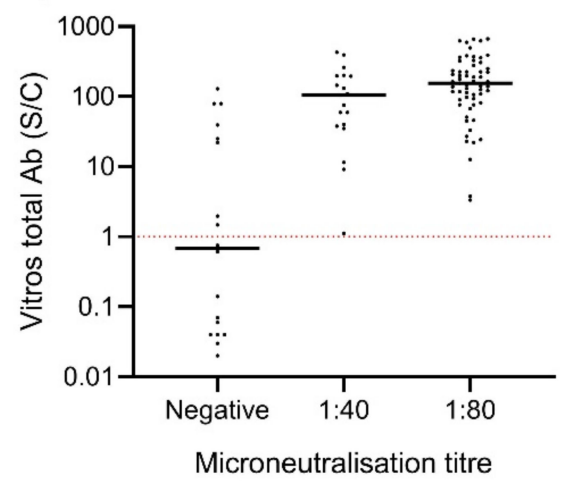

d)



f)

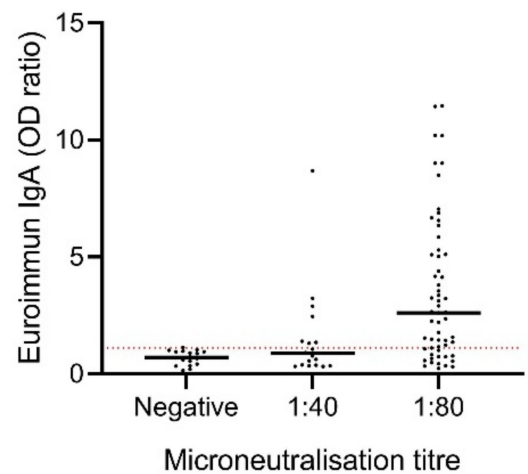

Figure 1. Signal cut-off and optical density ratios of SARS-CoV-2 enzyme immunoassays (EIA) at varying neutralising antibody titres. Serum from confirmed COVID-19 patients were assayed using microneutralisation and (a) Cobas Elecsys Anti-SARS-CoV-2, (b) Vitros Immunodiagnostic Anti-SARS-CoV-2, (c) Abbott Architect SARS-CoV-2 IgG, (d) an in-house IgG ELISA, (e) Euroimmun Anti-SARS-CoV-2 IgG ELISA and (f) Euroimmun Anti-SARS-CoV-2 IgA ELISA. Dashed line indicates the positive cut-off value of each assay determined by the manufacturer. The width of the scatter plot is proportionate to the number of data points at a given value, and the median EIA optical density shown. S/C, signal cut-off; OD, optical density. 
a)

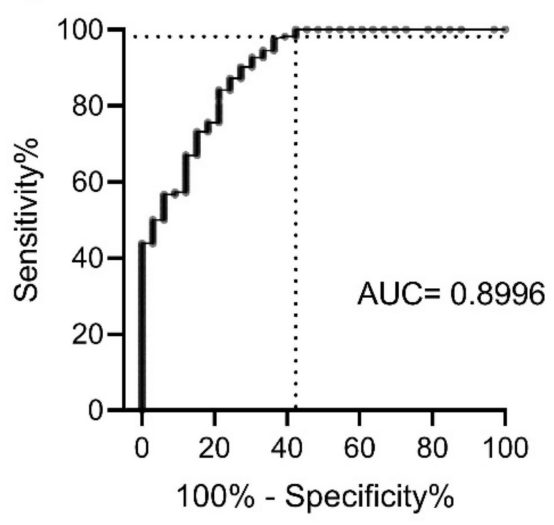

c)

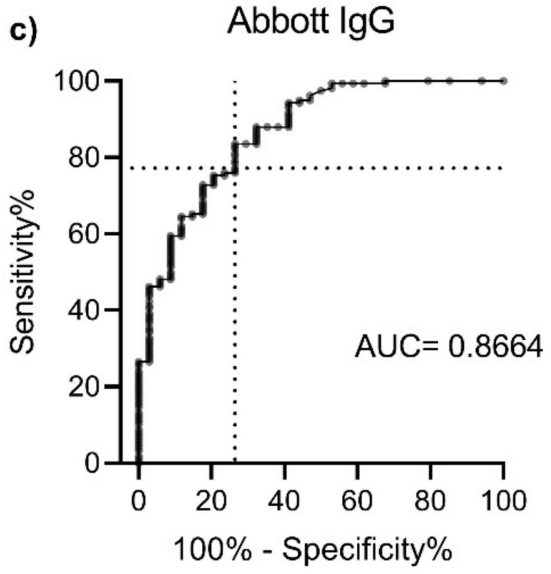

e)

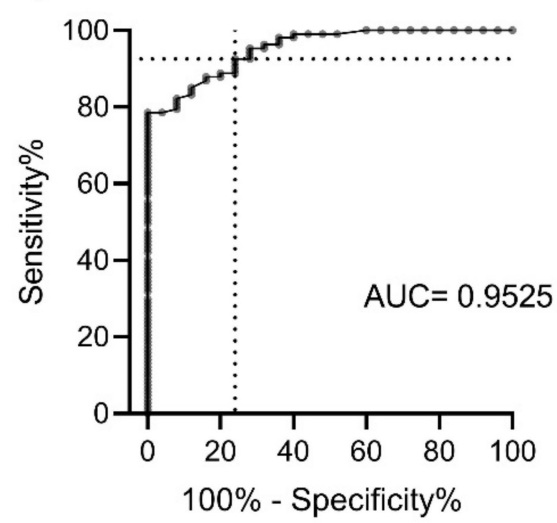

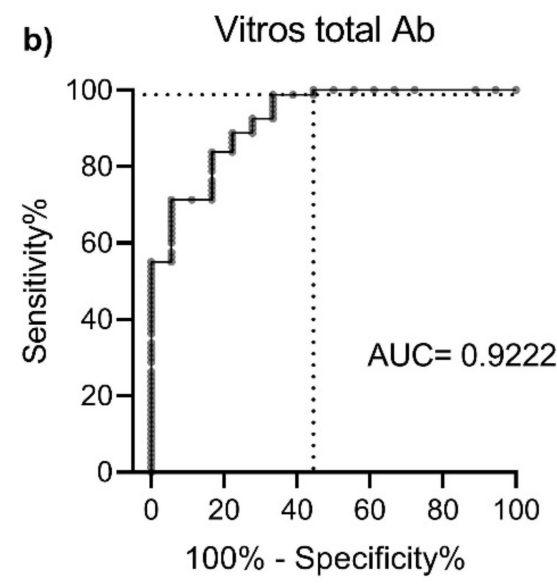

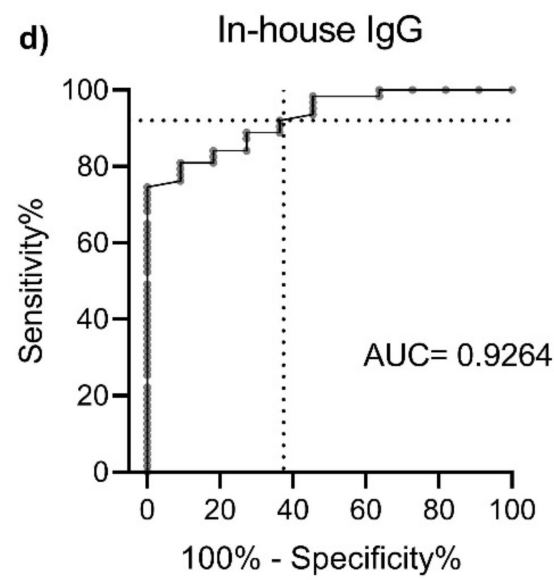

f)

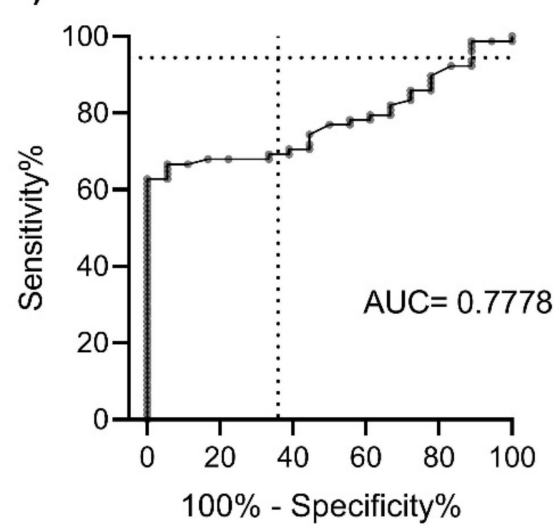

Figure 2. ROC curves for each enzyme immunoassay. (a) Cobas Elecsys Anti-SARS-CoV-2, (b) Vitros Immunodiagnostic Anti-SARS-CoV-2, (c) Abbott Architect SARS-CoV-2 IgG, (d) an in-house IgG ELISA, (e) Euroimmun Anti-SARS-CoV-2 IgG ELISA and (f) Euroimmun Anti-SARS-CoV-2 IgA ELISA. Note: Data are presented for up to 200 confirmed COVID-19 sera using microneutralisation as the reference standard. Euroimmun IgG had the best correlation with the detection of neutralising antibody (AUC $=0.9525$ ). The $95 \%$ confidence intervals of each assay were (a) $0.8400-0.9592,(\mathbf{b}) 0.8565-0.9880$, (c) $0.7986-0.9343$, (d) 0.8620-0.9908, (e) 0.9179-0.9871 and (f) 0.6870-0.8686. Dashed line represents assay performance at the positive cut-off value specified by the manufacturer. ROC, receiver operating characteristic; AUC, area under curve. 


\section{Discussion}

Serological assays need to have validated performance characteristics in assessing SARS CoV-2 infection for diagnosis, surveillance and correlation with other assays. Given neutralisation activity is important for immunity and for potential therapeutic options, such as convalescent plasma and immunoglobulin production, the major strength of our study is that it is among the few to validate serological assays for SARS-CoV-2 against a virus neutralisation test. On reference testing, neutralising antibodies were detected in $83 \%$ of samples, compared to EIA which detected SARS-CoV-2 antibodies in $91 \%$ of samples across all assays. This was unsurprising considering that not all patients with COVID-19 develop neutralising antibodies to infection [27]. For this reason, all assays produced false positives in reference to microneutralisation, with Euroimmun IgG displaying the highest positive predictive value and best correlation with neutralising antibody titres. Clinically, EIAs that correlate strongly with microneutralisation are of importance considering that the detection of neutralising antibodies may be useful in informing return to work and the discontinuation of transmission-based precautions [1].

For the aim of detecting protective neutralising antibodies, the S1-based Vitros Immunodiagnostic and the N-based Cobas Elecsys assays were most sensitive. A previous study suggested that assays targeting RBD and N proteins were more sensitive and better correlated with neutralisation titres than those targeting the S1 protein [23]. Our testing of 300 samples found assay sensitivity to be dependent on assay marker (total Ab vs. IgG vs. $\operatorname{IgA}$ ), and quantitative relationship dependent on the target antigen used-with the three spike-based assays best correlating with neutralising antibody titre (Figure 2).

In line with other validation studies using composite reference standards [28-30], the Euroimmun anti-SARS-CoV-2 IgG ELISA was highly sensitive and specific. However, the reported performance of the Euroimmun anti-SARS-CoV-2 IgA ELISA is mixed, and here, we found it to have low sensitivity. IgG response is longer lived [31], and these findings may be reflective of our cohort, which was primarily made up of convalescent serum collected more than 36 days following laboratory-confirmed infection. The performance of the Architect IgG assay in detecting neutralising antibody was moderate, and in convalescent samples, positivity was well below the sensitivity values advertised by the manufacturer ( $74 \%$ vs. $100 \%$ ). This highlights the importance of independent validation studies comparing a range of assays against multiple reference standards. Interestingly, there were five convalescent sera from reported laboratory-confirmed COVID-19 patients that returned negative results by microneutralisation and all EIAs tested. This also occurred in a validation study and could be explained by a failure to develop a measurable systemic antibody response, clearance of infection via other immune mechanisms or an initial false-positive RT-qPCR result [32]. Whilst donors in our study were required to confirm they had laboratory-confirmed infection to donate, proof in terms of visualisation of a hard copy of the donors' results did not occur. Therefore, it is possible that donors were non-compliant, or that the five samples in our study that were negative on all assays had a biological absence of antibodies.

All assays other than Euroimmun IgA displayed excellent specificity in testing a control cohort of pre-COVID-19 sera. The control cohort also included a small panel of non-SARS-CoV-2 sera positive for other respiratory virus antibodies, and we found no cross-reactivity on any of the assays used. Others have suggested that $\mathrm{S} 1$ and $\mathrm{N}$ are highly specific targets for SARS-CoV-2 serological analyses [23], and these antigens largely form the basis of current commercially available assays. A limitation of this work is that the timing of serum collection was not standardised, and that samples obtained were not tested equally across all assays due to limitations in sample volume and dead volume requirements of the automated EIAs. Nonetheless, the relatively large number of samples run remains a strength of this study, and allows for a head-to-head comparison of commercially available SARS-CoV-2 serological tests seen in few other studies.

We and others have shown that commercially available serological assays for SARSCoV-2 have varying performance that is dependent on both the platform and marker used. 
The assay chosen by end-users should be tailored to specific applications-for example, assays measuring antibodies to the nucleocapsid antigen might be best suited to disease surveillance as spike protein-based vaccines become available. During the COVID-19 pandemic, serological assays will be crucial in answering questions of immune protection against reinfection. If convalescent plasma or COVID-19 immunoglobulin is found to be a potentially effective therapeutic intervention, high throughput serological assays that closely correlate with neutralisation antibody levels are vital for scalability. As further testing platforms become available, validation studies such as this are needed to identify assays that inform on antibody titre and functionality.

Supplementary Materials: The following are available online at https:/ / www.mdpi.com/1999-491 $5 / 13 / 2 / 247 /$ s1. Table S1. Samples used to assess sensitivity and specificity of serological assays for SARS-CoV-2, Supplementary method, SARS-CoV-2 spike RBD protein production.

Author Contributions: W.D.R., A.D.K. and I.B.G. conceptualized the study; G.J.W., S.S.-B., Z.N., V.R. and W.D.R. developed the methodology; J.D., I.B.G., V.C.H., D.O.I. and J.M.P. oversaw participant recruitment and sample collection; G.J.W., Z.N., A.O.S., M.Y., J.C. and S.R.I. performed experiments; D.A. and R.A.B. provided experimental support and resources; G.J.W., Z.N., V.R. and V.C.H. performed data analysis; G.J.W., Z.N. and W.D.R. drafted the manuscript; W.D.R., A.D.K., S.T., J.D., I.B.G., V.C.H., D.O.I. and J.M.P. administrated and supervised the project; all authors reviewed and edited the manuscript. All authors have read and agreed to the published version of the manuscript.

Funding: This research received no external funding.

Institutional Review Board Statement: The study was conducted according to the guidelines of the Declaration of Helsinki. Ethics approval to compare and validate antibody SARS-CoV-2 assays as part of a larger project to collect, manufacture and supply convalescent plasma to patients enrolled in clinical trials and for COVID-19 Immunoglobulin was approved by the Lifeblood Ethics Committee (approval number: Hoad 30042020).

Informed Consent Statement: Informed consent was obtained from donors of convalescent plasma to Australian Red Cross Lifeblood.

Data Availability Statement: Data may be made available through contact with the corresponding author.

Acknowledgments: The authors would like to thank the Clinical Chemistry Laboratory at the Prince of Wales Hospital Randwick, the Reproductive Endocrinology Laboratory at the Royal Hospital for Women Randwick, and University of New South Wales Stats Central for their generous technical support. Australian Governments fund Australian Red Cross Lifeblood for the provision of blood, blood products and services to the Australian community.

Conflicts of Interest: The authors declare no conflict of interest.

\section{References}

1. Petherick, A. Developing antibody tests for SARS-CoV-2. Lancet 2020, 395, 1101-1102. [CrossRef]

2. Krammer, F.; Simon, V. Serology assays to manage COVID-19. Science 2020, 368, 1060-1061. [CrossRef]

3. Peeling, R.W.; Wedderburn, C.J.; Garcia, P.J. Serology testing in the COVID-19 pandemic response. Lancet Infect. Dis. 2020, 20, e245-e249. [CrossRef]

4. Maor, Y.; Cohen, D.; Paran, N. Compassionate use of convalescent plasma for treatment of moderate and severe pneumonia in COVID-19 patients and association with IgG antibody levels in donated plasma. EClinicalMedicine 2020, 26, 100525. [CrossRef]

5. Henderson, J.R.; Taylor, R.M. Arthropod-Borne Virus Plaques in Agar Overlaid Tube Cultures. Proc. Soc. Exp. Biol. Med. 1959, 101, 257-259. [CrossRef]

6. Stelzer-Braid, S.; Walker, G.J; Aggarwal, A. Virus isolation of severe acute respiratory syndrome coronavirus 2 (SARS-CoV-2) for diagnostic and research purposes. Pathology 2020, 52, 760-763. [CrossRef] [PubMed]

7. D'Cruz, R.J.; Currier, A.W.; Sampson, V.B. Laboratory Testing Methods for Novel Severe Acute Respiratory SyndromeCoronavirus-2 (SARS-CoV-2). Front. Cell Dev. Biol. 2020, 8, 468. [CrossRef]

8. Tan, C.W.; Chia, W.N.; Qin, X. A SARS-CoV-2 surrogate virus neutralization test based on antibody-mediated blockage of ACE2-spike protein-protein interaction. Nat. Biotechnol. 2020, 38, 1073-1078. [CrossRef]

9. Klasse, P.J. Neutralization of Virus Infectivity by Antibodies: Old Problems in New Perspectives. Adv. Biol. 2014, 2014, 157895. [CrossRef]

10. Houlihan, C.F.; Beale, R. The complexities of SARS-CoV-2 serology. Lancet Infect. Dis. 2020, 20, 1350-1351. [CrossRef] 
11. GeurtsvanKessel, C.H.; Okba, N.M.A.; Igloi, Z. An evaluation of COVID-19 serological assays informs future diagnostics and exposure assessment. Nat. Commun. 2020, 11,3436. [CrossRef]

12. Henss, L.; Scholz, T.; von Rhein, C. Analysis of humoral immune responses in SARS-CoV-2 infected patients. J. Infect. Dis. 2020, 223, 56-61. [CrossRef] [PubMed]

13. Luchsinger, L.L.; Ransegnola, B.; Jin, D. Serological Assays Estimate Highly Variable SARS-CoV-2 Neutralizing Antibody Activity in Recovered COVID19 Patients. J. Clin. Microbiol. 2020, 58, 12. [CrossRef]

14. Patel, E.U.; Bloch, E.M.; Clarke, W. Comparative performance of five commercially available serologic assays to detect antibodies to SARS-CoV-2 and identify individuals with high neutralizing titers. J. Clin. Microbiol. 2020, 59, e02257. [CrossRef] [PubMed]

15. Weidner, L.; Gänsdorfer, S.; Unterweger, S. Quantification of SARS-CoV-2 antibodies with eight commercially available immunoassays. J. Clin. Virol. 2020, 129, 104540. [CrossRef] [PubMed]

16. Jääskeläinen, A.J.; Kuivanen, S.; Kekäläinen, E. Performance of six SARS-CoV-2 immunoassays in comparison with microneutralisation. J. Clin. Virol. 2020, 129, 104512. [CrossRef]

17. Brigger, D.; Horn, M.P.; Pennington, L.F. Accuracy of serological testing for SARS-CoV-2 antibodies: First results of a large mixed-method evaluation study. Allergy 2020. [CrossRef]

18. Kohmer, N.; Westhaus, S.; Rühl, C.; Ciesek, S.; Rabenau, H.F. Brief clinical evaluation of six high-throughput SARS-CoV-2 IgG antibody assays. J. Clin. Virol. 2020, 129, 104480. [CrossRef]

19. Kohmer, N.; Westhaus, S.; Rühl, C.; Ciesek, S.; Rabenau, H.F. Clinical performance of different SARS-CoV-2 IgG antibody tests. J. Med. Virol. 2020, 92, 2243-2247. [CrossRef]

20. Marklund, E.; Leach, S.; Axelsson, H. Serum-IgG responses to SARS-CoV-2 after mild and severe COVID-19 infection and analysis of IgG non-responders. PLoS ONE 2020, 15, e0241104. [CrossRef]

21. Lumley, S.F.; Eyre, D.W.; McNaughton, A.L. SARS-CoV-2 antibody prevalence, titres and neutralising activity in an antenatal cohort, United Kingdom, 14 April to 15 June 2020. Eurosurveillance 2020, 25, 2001721. [CrossRef]

22. Meschi, S.; Colavita, F.; Bordi, L. Performance evaluation of Abbott ARCHITECT SARS-CoV-2 IgG immunoassay in comparison with indirect immunofluorescence and virus microneutralization test. J. Clin. Virol. 2020, 129, 104539. [CrossRef]

23. Okba, N.M.A.; Müller, M.; Li, W. Severe Acute Respiratory Syndrome Coronavirus 2-Specific Antibody Responses in Coronavirus Disease Patients. Emerg. Infect. Dis. J. 2020, 26, 1478. [CrossRef]

24. Grzelak, L.; Temmam, S.; Planchais, C. A comparison of four serological assays for detecting anti-SARS-CoV-2 antibodies in human serum samples from different populations. Sci. Transl. Med. 2020, 12, 559. [CrossRef]

25. Padoan, A.; Bonfante, F.; Sciacovelli, L.; Cosma, C.; Basso, D.; Plebani, M. Evaluation of an ELISA for SARS-CoV-2 antibody testing: Clinical performances and correlation with plaque reduction neutralization titer. Clin. Chem. Lab. Med. 2020, 58, e247. [CrossRef]

26. Peterhoff, D.; Glück, V.; Vogel, M. A highly specific and sensitive serological assay detects SARS-CoV-2 antibody levels in COVID-19 patients that correlate with neutralization. Infection 2020, 49, 75-82. [CrossRef]

27. Robbiani, D.F.; Gaebler, C.; Muecksch, F. Convergent antibody responses to SARS-CoV-2 in convalescent individuals. Nature 2020, 584, 437-442. [CrossRef]

28. Beavis, K.G.; Matushek, S.M.; Abeleda, A.P.F. Evaluation of the EUROIMMUN Anti-SARS-CoV-2 ELISA Assay for detection of IgA and IgG antibodies. J. Clin. Virol. 2020, 129, 104468. [CrossRef]

29. Haselmann, V.; Kittel, M.; Gerhards, C. Comparison of test performance of commercial anti-SARS-CoV-2 immunoassays in serum and plasma samples. Clin. Chim. Acta 2020, 510, 73-78. [CrossRef]

30. Charlton, C.L.; Kanji, J.N.; Johal, K. Evaluation of six commercial mid to high volume antibody and six point of care lateral flow assays for detection of SARS-CoV-2 antibodies. J. Clin. Microbiol. 2020, 58, e01361. [CrossRef]

31. Hsueh, P.R.; Huang, L.M.; Chen, P.J.; Kao, C.L.; Yang, P.C. Chronological evolution of IgM, IgA, IgG and neutralisation antibodies after infection with SARS-associated coronavirus. Clin. Microbiol. Infect. 2004, 10, 1062-1066. [CrossRef]

32. Ainsworth, M.; Andersson, M.; Auckland, K. Performance characteristics of five immunoassays for SARS-CoV-2: A head-to-head benchmark comparison. Lancet Infect. Dis. 2020, 20, 1390-1400. [CrossRef] 